\title{
MANAGEMENT OF SPINAL GUNSHOT WOUND INJURIES
}

\author{
MANEJO DAS LESÕES POR ARMA DE FOGO NA COLUNA VERTEBRAL \\ MANEJO DE LESIONES POR ARMA DE FUEGO EN LA COLUMNA

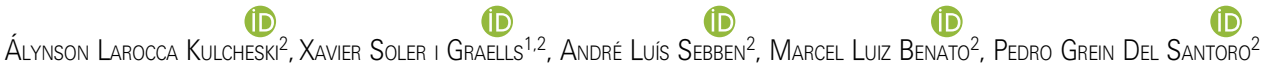 \\ 1. Universidade Federal do Paraná, Hospital de Clínicas, Curitiba, Paraná, Brazil. \\ 2. Hospital do Trabalhador, Curitiba, Paraná, Brazil.
}

\begin{abstract}
Objectives: Elaborate a care protocol for spinal gunshot wounds (GSWs), based on the experience of more than fifteen years of treating this type of injury. Methods: A retrospective cross-sectional analysis of the electronic medical record data of a tertiary hospital related to the treatment of spinal GSWs between January 2002 and January 2018. Results: The management proposed was applied to 700 patients. Epidemiological data collected describes the population served. Conclusions: An easy-to-use treatment flowchart was developed that, according to factors related to the neurological condition, projectile location, lesion stability and additional criteria, allows the objective determination of the best treatment option for each case. Level of evidence II; Retrospective Study.
\end{abstract}

Keywords: Wounds, Gunshot; Spine; Protocols.

\section{RESUMO}

Objetivos: Elaborar um protocolo de atendimento para ferimentos por arma de fogo (FAF) na coluna vertebral, com base na experiência de mais de quinze anos de atendimento desse tipo de lesão. Métodos: Realizou-se uma análise transversal retrospectiva dos dados do prontuário eletrônico de um hospital terciário referentes ao atendimento de FAF na coluna vertebral entre janeiro de 2002 e janeiro de 2018. Resultados: O manejo proposto foi aplicado a 700 pacientes. Os dados epidemiológicos coletados mostram a população atendida. Conclusões: Foi elaborado um fluxograma de tratamento de uso fácil que, de acordo com fatores relacionados com o quadro neurológico, a localização do projétil, a estabilidade da lesão e critérios adicionais, permite determinar objetivamente a melhor opção de tratamento para cada caso. Nível de evidência II; Estudo Retrospectivo.

Descritores: Ferimentos por Arma de Fogo; Coluna Vertebral; Protocolos.

\section{RESUMEN}

Objetivos: Desarrollar un protocolo de atención a las heridas por arma de fuego (HAF) en la columna vertebral, basado en la experiencia de más de quince años en la atención a este tipo de lesiones. Métodos: Se realizó un análisis transversal retrospectivo de los datos de la historia clínica electrónica de un hospital terciario sobre la atención en casos de HAF en la columna vertebral entre enero de 2002 y enero de 2018. Resultados: Se aplicó el tratamiento propuesto a 700 pacientes. Los datos epidemiológicos recopilados muestran la población atendida. Conclusiones: Se desarrolló un diagrama de flujo de tratamiento de fácil de usar que, de acuerdo a factores relacionados con la condición neurológica, ubicación del proyectil, estabilidad de la lesión y criterios adicionales, permite determinar objetivamente la mejor opción de tratamiento para cada caso. Nivel de evidencia II; Estudio Retrospectivo.

Descriptores: Heridas por Arma de Fuego; Columna Vertebral; Protocolos.

\section{INTRODUCTION}

The incidence of violent crimes among the civil populations ${ }^{1}$ of all countries has increased every year and, along with it, an increase in the rate of gunshot wounds (GSW) to the spine. ${ }^{2}$ It is estimated that each year about $17 \%$ of spinal cord traumas are caused by this injury mechanism ${ }^{1,2}$ and it is the second most common cause of spinal cord injuries, surpassed only by automobile accidents. ${ }^{3}$

These injuries mainly affect young males between 15 and 34 years of age and predominantly involve the thoracic segment (usually T12), with complete neurological deficit in $70 \%$ of cases. ${ }^{2-8}$.
North American statistics estimate that 200,000 people live with spinal cord injuries, generating expenses that can reach up to US\$1,350,000.00. ${ }^{9}$

Because of the relevance of these injuries and the complexity involved in treating them, it is necessary to develop guidelines targeting better outcomes. ${ }^{10}$

The Hospital do Trabalhador $(\mathrm{HT})$ currently responds to about $60 \%$ of trauma care cases in the metropolitan region of the city of Curitiba (Paraná-Brazil), which, according to IBGE 2017 estimates, has a population of 3.5 million inhabitants. ${ }^{11}$ There has been a 
significant increase in spinal GSW injuries, given that in 2007 they were the cause of $5 \%$ of spine fractures and in 2015 they accounted for $15 \%$ of them. ${ }^{12}$

Established protocols for approaching the treatment of victims of spinal GSW are scarce in the medical literature.

The main objective of this study is to present a protocol for the assessment, diagnosis and management of patients who are victims of spinal gunshot wounds. The secondary objective is to document the epidemiological profile of the patients who are victims of these spinal injuries.

\section{METHODS}

Patients who were victims of spinal gunshot wounds and underwent treatment at a tertiary trauma care referral hospital between January 2002 and January 2018 were evaluated. This study was approved by the Institutional Review Board (IRB) as CAAE number 50834415.8.0000.5225.

A retrospective cross-sectional analysis of the Hospital do Trabalhador electronic medical record data for these patients was conducted.

The following data were obtained: age, sex, comorbidities, day of the week of the incident, means of transport to the hospital, topography of the injury, neurological status, associated injuries and whether a surgical approach was performed. The GSWs were divided according to the presence of a lodged projectile or a transfixing wound. The reason for the GSWs were classified as the result of a robbery, fight, attempted murder, police confrontation or unknown. Hospitalization time and complications associated with the trauma were also analyzed.

Patients of all age groups were included and patients with incomplete medical record data were excluded.

The treatment of all patients was supervised by a team of spine surgeons from a tertiary hospital accredited for spinal surgery training by the Brazilian Spine Society, a specialty society comprised of five preceptors and four trainee physicians, who remain in the service for two years.

Based on the data obtained, the 15 years of service experience and the bibliographical review, we prepared a service protocol in flowchart format (Figure 1). Three variables were considered for surgical indication: neurological status, spinal stability and location of the projectile. Other factors, such as active cerebrospinal fluid leakage, lead poisoning or intradiscal or spinal canal lead corrosion and prolapsed disc caused by the GSW were also considered, although they rarely occur.

Quantitative data analysis was performed on SPSS Statistics 1.7 software using means and standard deviations for continuous variables and percentage values.

\section{RESULTS}

The total sample consisted of 998 patients, 700 of whom were included in and 298 of whom were excluded from the study.

The distribution shows the prevalence of involvement by males, with 666 patients $(95.1 \%)$ compared to females, with 34 patients (4.9\%). Ages ranged from 9 to 68 years, with a mean age of 21 years. Most victims ( $n=644,92 \%)$ were brought to the hospital by ambulances from the emergency rescue service of the state and municipal care network, while 56 patients (8\%) arrived by other means. Four hundred and six patients (58\%) were injured on the weekend. In terms of the occurrence of associated injuries, it was found that $41 \%$ of the patients had only spinal injuries. A wide variety of associates injuries was registered for the other $59 \%$, with abdominal and chest injuries being more common (Figure 2). As to the cause of the gunshots, 448 cases (64\%) occurred during robberies, 168 cases (24\%) due to fights/attempted homicide, and $84(12 \%)$ were classified as cause unknown. No cases resulting from police confrontation were reported.



Figure 1. Algorithm for deciding whether to perform surgery for spinal GSW. 


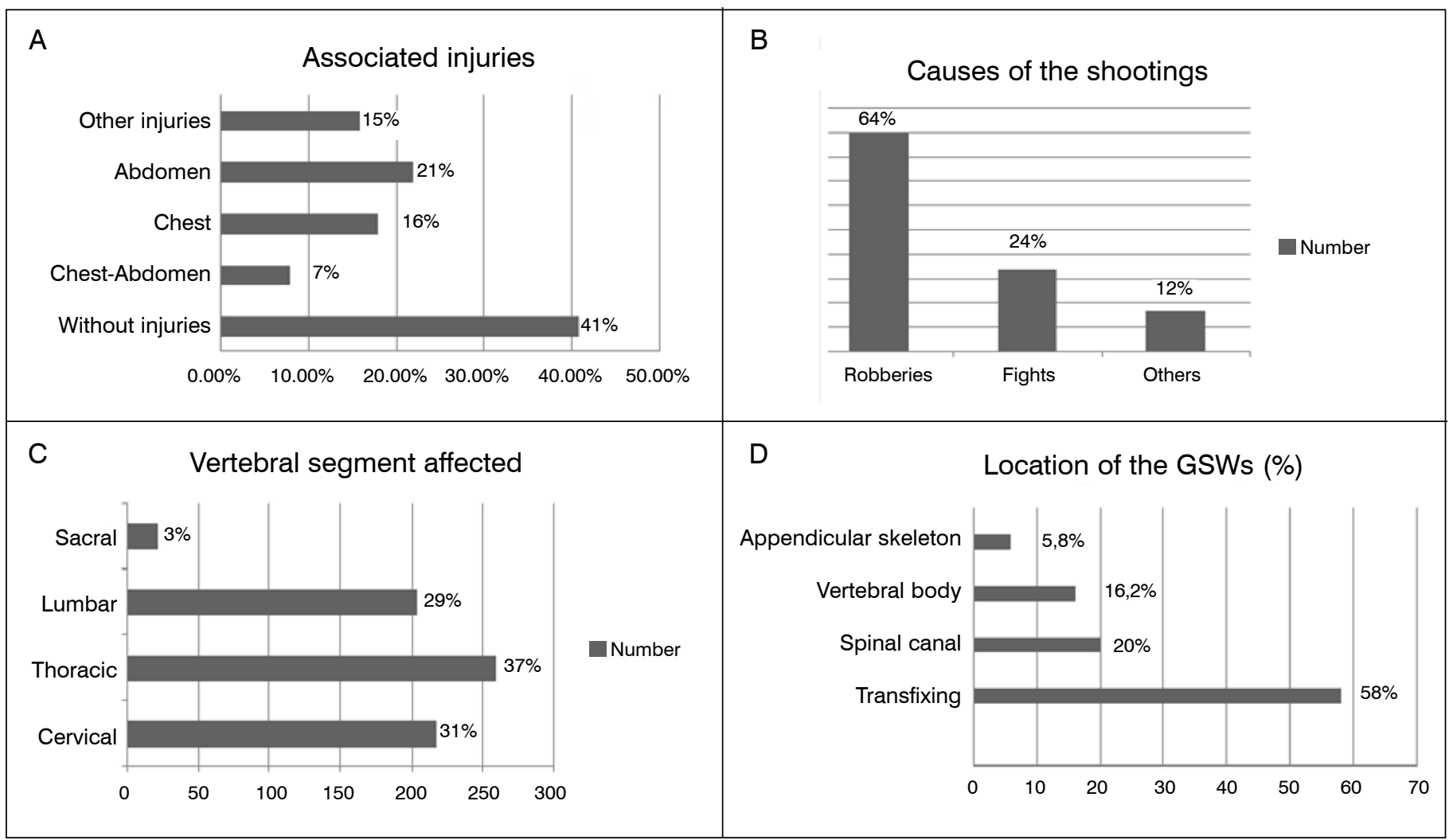

Figure 2. (A) Percentage of associated injuries, (B) Causes of the shootings, (C) Vertebral segment, (D) Location of the GSW.

In the analysis of vertebral segments affected, the thoracic segment was the most affected (259 cases: $37 \%$ ), followed by the cervical segment (217 cases: $31 \%$ ), the lumbar segment (203 cases: $29 \%$ ) and, finally, the sacral segment (21 cases: $3 \%)$. The most often affected vertebral level in the thoracic spine was T12 (27\%), in the cervical spine was C5 (43\%) and in the lumbar spine was L3 (31\%).

Neurological deficit was documented in most of the study patients, in a total of 434 patients (62\%), with complete lesion being the most frequently observed grade (Frankel A - 307 patients: $70.8 \%$ ) (Figure 3). Transfixing GSWs were the most common, accounting for $58 \%$ of cases. In the remaining cases, about 140 (20\%) projectiles were lodged in the spinal cord canal, $113(16.2 \%)$ penetrated the vertebral body remaining intraosseous and 41 (5.8\%) hit posterior elements or appendicular skeleton.

Most of the victims (412 patients - 58.8\%) were treated conservatively. Surgical treatment was necessary in the remaining cases (288 patients - 41.2\%) (Figure 4). All the projectiles removed during surgical treatment were sent for ballistic analysis. This examination proved that the projectiles were from low-energy civilian-use firearms (Figure 5).

Instrumentation was required in 115 cases. All the projectiles lodged in the spinal cord canal were removed and stabilization via instrumentation was required in 23 cases. Among the transfixing projectiles, 45 caused unstable fractures that required spinal instrumentation. There was significant destruction of the vertebral bodies caused by 27 intrabone projectiles that required surgical procedures to remove the projectiles and stabilize the spinal segment. The other 11 projectiles remained in contact with the intervertebral disc and were also removed. Nine projectiles were lodged in the interior of the dura mater and were removed after wide laminectomy followed by durotomy and dural closure. In these cases, arthrodesis was necessary because of the wide laminectomy performed, which generated secondary instability (Figure 4).

Hospital stays lasted an average of 10 days, ranging from 2 to 93 days. There were 105 cases with complications, the most serious being 56 deaths due to the GSW affecting other vital structures,

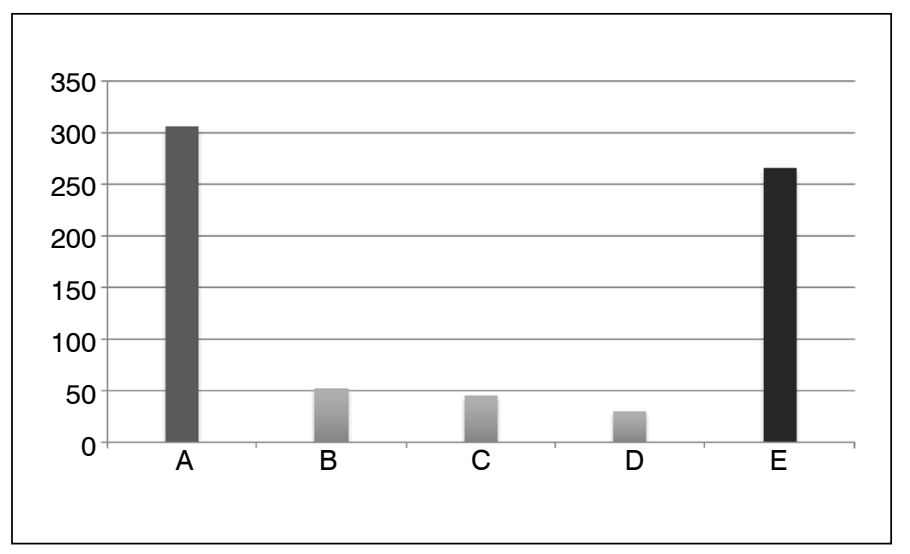

Figure 3. Distribution of the associated neurological injuries (according to the Frankel neurological scale).

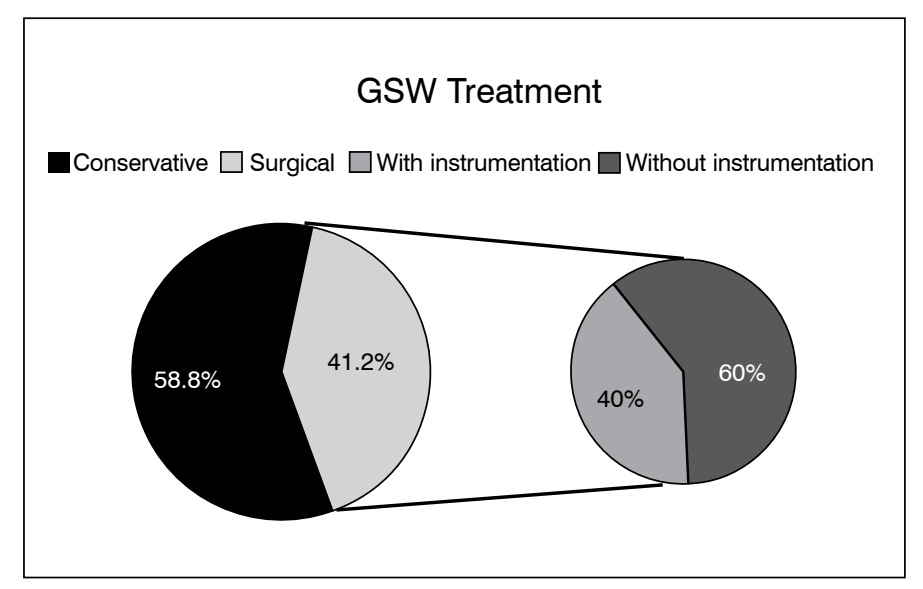

Figure 4. Percentage of patients treated conservatively and surgically and who need segmental instrumentation. 


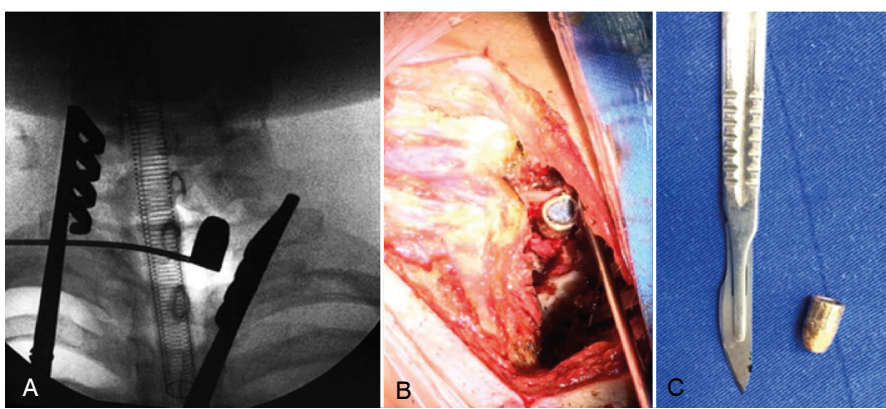

Figure 5. Images of the projectile A) radioscopic, B) intraoperative, C) projectile removed from the cervical region and sent for ballistic analysis.

nine cases of meningitis and six cases of infectious discitis. One patient presented an exceedingly rare complication, which was the diffusion of lead through the disc and spinal canal after it corroded, which neither required a surgical approach nor evolved with neurological deficit or systemic lead poisoning (Figure 6). The other complications were infectious, all in patients who had had previous injuries associated with abdominal viscera, and they were treated with specific antibiotics with satisfactory improvement. Five of the six cases of infectious discitis secondary to GSW underwent surgical debridement and one case was resolved with specific antibiotic therapy during hospitalization with no surgical approach performed. Intravenous corticosteroid therapy was not used in any of the patients.

\section{Treatment protocol}

The HT protocol for treating patients with GSW spinal injury was based on a literature review and the report of the experience managing this type of injury performed by a uniform team. The overall assessment of the patients took the priorities related to the treatment of this injury into account. It was applied to 700 patients, demonstrating the prevalence of this type of care.

\section{Initial care}

The initial treatment of a patient with a spinal GSW injury must include the standard trauma protocols established by the ATLS Advanced Trauma Life Support. ${ }^{13}$

Fractures caused by GSW are generally stable. ${ }^{8}$ The evaluation of spinal injury must be made after hemodynamic stabilization. In paraplegic or quadriplegic patients, the assessment of these items can be difficult, given the loss of visceral sensitivity. ${ }^{2}$

The gathering of information from the pre-hospital care team, such as type of weapon used, number of shots fired, and proximity of the shot(s), should be an integral part of the initial evaluation. ${ }^{14}$ This information provides guidance about the extent and severity of the injuries (civilian vs. military use weapon, for example).

The complete neurological examination must be performed to document motor function, reflexes and sensitivity at the time of the injury and should be repeated periodically. The bulbocavernosus reflex should be tested to check the period of spinal shock.

Tetanus prophylaxis is necessary. Broad-spectrum antibiotics should be started early. Corticosteroids should not be included in the therapeutic regime for patients with GSW, as has been established in the literature. ${ }^{15}$

\section{Imaging}

The entry and exit point of the wounds must be inspected and radiopaque markers are placed over the wounds to identify the trajectory of the projectile in radiographic studies. Orthogonal radiographic views of the spine should be obtained to locate the projectile and detect any fractures (Figure 7). This should be followed by computed axial tomography (CAT), which allows for greater precision in the location of projectile fragments within the spinal canal or vertebral segments (Figure 8). If instability is suspected, flexion and extension radiographs can be performed.

The use of magnetic resonance was not included in our protocol.

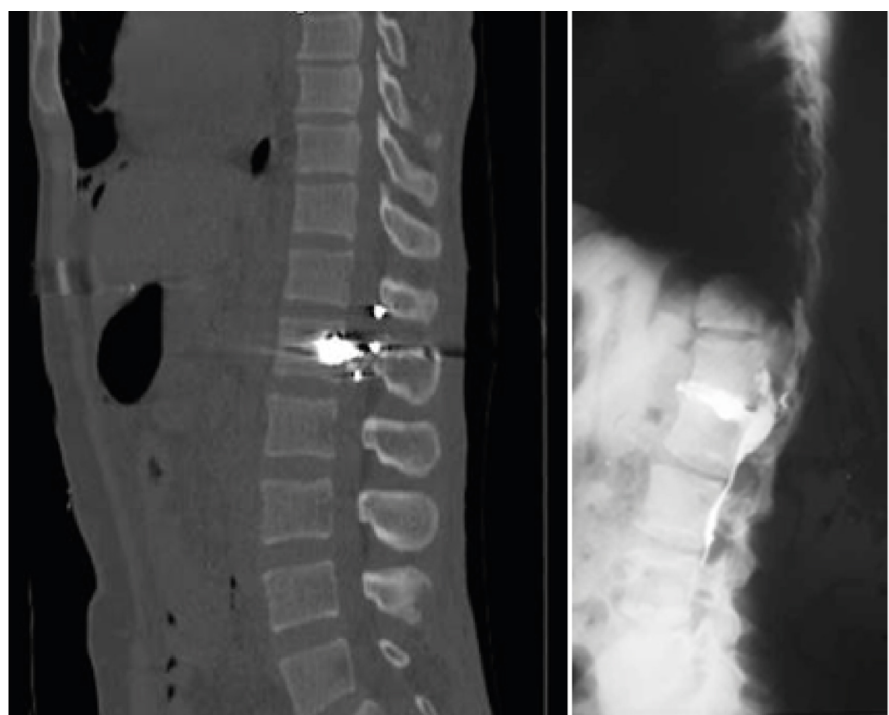

Figure 6. Patient with projectile lodged in the disc space, which evolved with corrosion of the projectile and diffusion of lead into the disc and spinal canal.
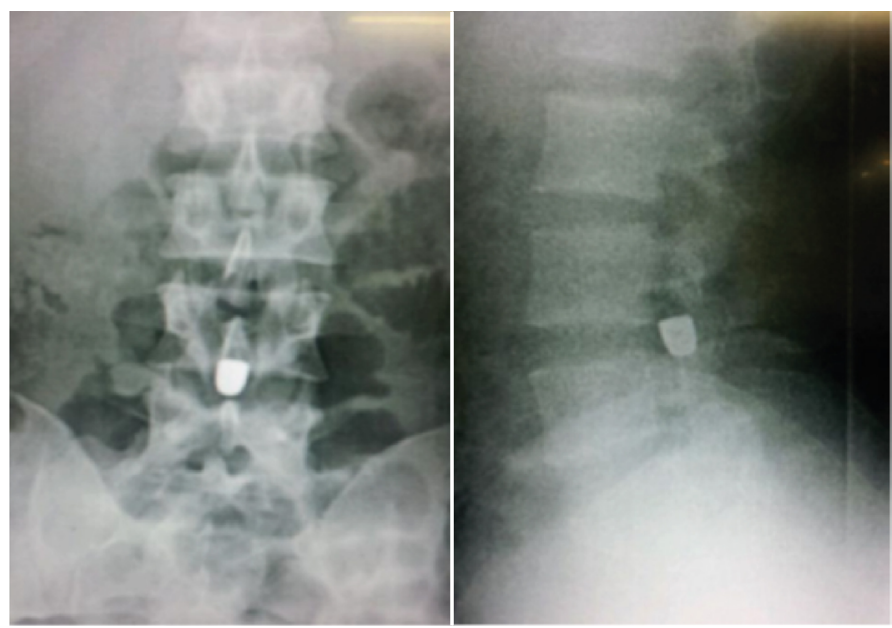

Figure 7. Lumbar radiograph in orthogonal incidences with intracanal projectiles between L4-L5.

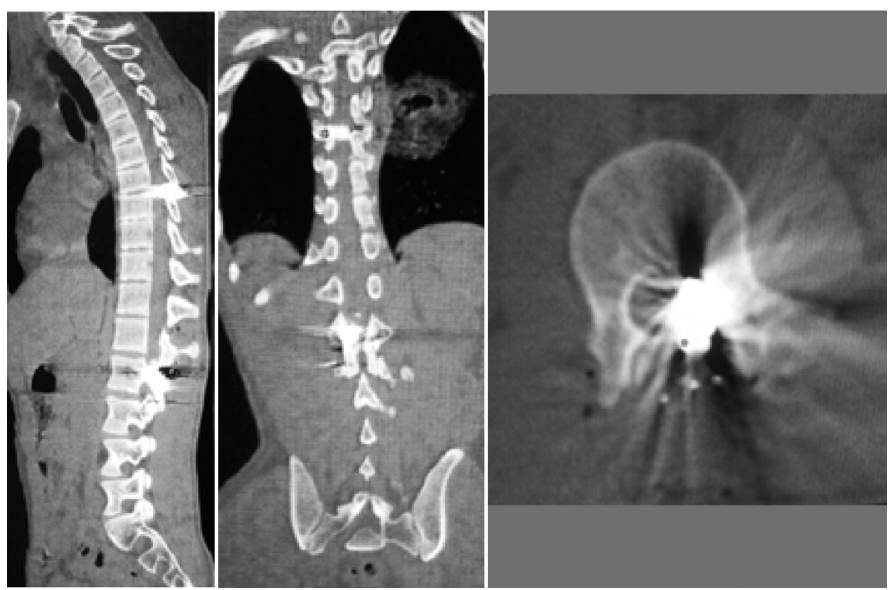

Figure 8. Sagittal/coronal/axial CAT showing the peculiarity of two projectiles (L2 and between T8-T9), both intracanal.

\section{Treatment}

Following the protocol used over the past 15 years, four situations were the most common:

1. Patients with spinal GSW associated with the perforation of 
abdominal viscera underwent intravenous broad-spectrum antibiotic therapy, covering gram-positive (80\% of cases) and gram-negative germs, for two weeks to prevent systemic infection, regardless of the need for intervention surgery (Figure 1).

2. Patients with transfixing GSW, without the presence of bone fragments or an intracanal projectile, received conservative treatment, unless they displayed progressive neurological deficit and segmental instability, receiving antibiotic prophylaxis and neurovascular observation for 48 hours, followed by reevaluation on an outpatient basis.

3. Patients with projectile or fragments (of bone, disc or projectile) inside the intervertebral canal were treated surgically, with decompression and removal of the projectile and/or fragments. If there was instability or if instability was caused by the surgery, the segment was instrumented.

4. Patients with GSW presenting a projectile in the intervertebral space (disc) or in contact with the facet joints underwent surgery to remove the projectile in order to prevent lead poisoning or its diffusion into the disc and spinal canal (Figure 3). When there was instability or if instability was caused by the surgery, segmental instrumentation was performed.

\section{Surgical time}

We indicate surgery as early as possible depending on the clinical and hemodynamic stability of the patient. The patient is observed for at least 48 hours and entered into a multidisciplinary rehabilitation program (social services/nursing/physical therapy/medical clinic), paying special attention to urological, and cardiorespiratory function and injuries such as pressure ulcers, especially in patients with neurological changes.

\section{DISCUSSION}

Gunshot injuries in the spine were mainly seen in military populations. Currently, with the greater spread of and access to firearms in the civilian population in general, the number of these injuries is growing, causing from 13 to $17 \%$ of traumatic spinal injuries. ${ }^{16,17}$ The literature shows that the incidence of these injuries is disproportionally higher in males, at more than $80 \%$ of cases. As regards age, they are most prevalent in the third decade of life. ${ }^{18}$ All these data are corroborated by the present study. Men are more impacted by high-energy traumas because of their greater exposure to danger. When added to the fact that they are economically active patients and that many, in the age group most affected, are the central economic pillar of their nuclear family, it has great potential for an additional social problem. The repercussions of GSWs transcend the medical environment.

The vertebral segment most affected by spinal GSWs is thoracic spine, followed by the cervical and lumbosacral segments. The literature reports thoracic incidence at around $55 \%$, followed by cervical at $25 \%$ and lumbosacral at $20 \%$. This study confirmed the data previously presented in the literature. It is believed that gunshot wounds occur mainly in the thoracic region because shooters target the chest more frequently, followed by the region of the craniocervical transition. ${ }^{19}$ Because the thoracic region is the most exposed, and consequently an easier target for the shooter, the fact that most GSWs occurred in the thoracic spine is justified. In contrast, the appendicular skeleton is the least affected due to its continuous movement during flight and smaller area.

Radiographic and tomographic examinations were routinely performed on patients suffering from GSWs. The use of magnetic resonance is not recommended in these cases due to the risk of projectile or fragment migration, which has the potential to cause neurological deficit or worsen the existing deficit. This examination also will present artifacts due to the presence of metallic elements, which hinders proper interpretation. Research has shown that the magnetic resonance examination does not change the treatment approach in GSW victims, in addition to its being more time consuming and more expensive. ${ }^{4}$ Most hospitals in Brazil and in de- veloping countries have financial difficulties and the few resources are generally concentrated in large urban centers. The protocol presented aims to reach all levels of care for this injury and outline a suitable and reproducible conduct without burdening the healthcare system. Therefore, it is not indicated.

The treatment of patients who are victims of spinal GSWs should be individualized. After treating life-threatening injuries and following the ATLS routines, the neurological status, spinal stability, whether there is spinal cord compression, and the location of the projectile should be assessed. When the injuries are stable and there is no deficit or neurological compression, conservative treatment is indicated. In cases where these criteria are not met or other complications arise (for example, cerebrospinal fluid fistula, lead poisoning), surgical treatment is indicated. Surgical indications for the treatment of GSWs are still controversial, but many authors corroborate the benefits of the approach. The literature clearly shows that the objectives of surgical treatment for patients who are victims of GSWs are to decompress the spinal canal, stabilize the spine when unstable, remove the projectile when located in a topography that could cause complications (disc and joint space, compression of neurological structures) and thus, offer the greatest chances for neurological recovery and prevent other complications that could result from this injury. ${ }^{20}$ Benzel et al., ${ }^{12}$ showed that up to $86 \%$ of patients with incomplete lesions improved with surgical decompression. Barros Filho et al., ${ }^{4}$ described recommendations for surgery in cases with laminar fractures with extrinsic compression. Waters and Sie reported benefits from spinal cord decompression of T12 to $L 4$ and the main approach in these cases was isolated decompressive laminectomy. ${ }^{21}$ This study showed that $41.2 \%$ of patients suffering from spinal GSWs underwent surgery. The most common reason for this indication was compression of neural structures, followed by unstable fractures, which is consistent with the literature data. Currently, we are seeing a worldwide increase in indications for surgical treatment of the spine. ${ }^{22}$ The United States has the highest rate of spine surgeries in the world, with indications of spinal arthrodesis surgery having undergone the highest increase, tripling in the 1990s. ${ }^{23}$ We have noticed a growing trend to recommend a surgical approach to treat spinal GSWs over the years. Although the literature does not consistently prove its effectiveness in neurological improvement, we believe that the surgical procedure has a low risk of complications and the surgical techniques are well established. Stabilization of the spinal segment, when indicated, provides an earlier and more effective rehabilitation. We did not conduct a longitudinal comparative study of the clinical outcomes of surgically versus conservatively treated patients, which we view as a limitation of our study. We suggest the development of new studies with this objective.

Instability, as a criterion in cases of firearm wounds, is not welldefined, since the projectiles determine a directional force in a static spine and are less likely to cause instability, even with an injury to two or three spines, as defined by Denis. ${ }^{20}$ About $60 \%$ of the patients operated underwent instrumentation. Of these, $39 \%$ were instrumented because of unstable fractures and, in the other cases, fixation was performed due to surgical access ample enough for canal decompression and projectile removal, causing instability in the segment being operated to treat the injury. In a study by Stauffer et al., it was demonstrated that most cases of postoperative iatrogenic instability related to GSWs of the spine result from excessively large decompressions. ${ }^{7}$ A fact that may justify extensive decompression is the possibility of the projectile having shifted intradurally. ${ }^{24}$ With the goal of preventing instability and postoperative deformities in cases where more extensive decompressions were necessary or uni- or bilateral facetectomy was necessary, a decision was made to perform an arthrodesis procedure. It is believed that instrumentation in order to relieve the affected nerve structures has a favorable cost-benefit ratio.

The literature regarding the time to perform surgical treatment for victims of spinal GSWs is scarce and inaccurate. Feehlings et al., 
showed that, in patients who are victims of non-penetrating trauma to the spine and who present neurological injuries, the ideal time for surgical treatment would be within 24 hours following the trauma. ${ }^{25}$ In patients with GSWs, this period is not accurate. Early approaches can increase the incidence of cerebrospinal fluid fistulas when the projectile has injured the dura mater. In late approaches, on the other hand, after more than two weeks, the incidence of arachnoiditis and infection increases. ${ }^{2}$ Looking for the window of opportunity for a surgical approach to the trauma is recommended. These patients are usually serious and risk clinical instability if handled in an untimely manner and not at the appropriate time. When the patient is clinically unstable, we recommend the earliest approach possible. Specifically, in cases where the projectile is located intradurally, when there is no progressive neurological deficit, we recommend waiting for 2 to 5 days in order to reduce the possibility of CSF fistulas. In our series, we did not have any case that evolved to a persistent cerebrospinal fluid fistula requiring a surgical approach. We are aware of this increased risk in earlier approaches, but we did not observe an increased incidence in our series.

Among the possible complications related to GSWs, the most notable is lead poisoning, a condition caused by the accumulation of lead in the organism. It can cause anemia, abdominal pain, lethargy and neurological changes. In general, it occurs when the projectile is lodged in the joints and the synovial fluid dissolves the lead or when it is in the disc space. The symptoms can occur up to 40 years after the injury. The exact incidence of these intoxications is unknown. In the present study there was one case in which there was corrosion of the lead in the spinal canal. However, no patient had lead poisoning, including this case, nor was surgery required for this situation. ${ }^{26}$ The patient remained in stable condition throughout follow-up and did not develop any clinical or neurological changes. It is considered rare, but if it presents the patient must be monitored frequently for lead poisoning and neurological changes.

Intravenous corticosteroid therapy was not used in any patient, in accordance with hospital protocol and the recommendations in the literature. ${ }^{14}$ The use of corticosteroids in penetrating trauma is related to an increased risk of infections, gastrointestinal complications and pancreatitis. ${ }^{27}$ Due to the modest differences in the treatments, the results do not suggest clinical benefits. Corticosteroid use is associated with an increased risk of pulmonary complications and gastrointestinal bleeding in patients around 60 years of age.$^{28}$ Corticosteroid therapy is not indicated even for incomplete lesions. Levy et al., reviewed 252 cases of spinal cord injuries from firearms and concluded that methylprednisolone did not change the prognosis even in incomplete lesions, similar to the findings of Heary et al., ${ }^{27,14}$ In view of the evidence in the literature, its use is not recommended.

Tetanus prophylaxis and antibiotic therapy are recommended, varying from two to three days for injuries without hollow viscera involvement to 7 to 14 days when there is injury to the hollow viscera or colon perforation. The choice of antibiotic varies according to the site of the wound and additional injuries.
Various combinations can be used, the most common being cefotaxime, gentamicin, clindamycin and penicillin. The infection rate for this type of injury ranges from 7 to $22 \% .{ }^{29}$ In the experience presented here, the incidence of infectious complications was $14.2 \%, 60 \%$ of which were related to meningitis and $40 \%$ to spondylodiscitis. All patients who had infectious complications had hollow viscera perforated by the projectile, denoting more severe injuries. Even in the absence of a surgical indication at the outset, the patient should remain in the hospital and then continue to be monitored in frequent outpatient follow-ups, given the risk of infection, which can often prove insidious and require a subsequent surgical approach as a result of clinical deterioration, such as spondylodiscitis or meningitis.

Few protocols and algorithms targeting the treatment of spinal gunshot injuries are found in the literature. Jaiswal et al. presented a protocol similar to that of the present study focusing on the management of these injuries. In contrast to most of the algorithms found in the literature, they suggest a protocol based on the experience with a large number of spinal GSW victims treated over a period of more than 15 years. Many algorithms are based on a small number of cases or do not cite the experience of a specialized center. ${ }^{15}$ An AOSpine study demonstrated a reproducible algorithm with a clear strategy for surgical indications. ${ }^{30}$ In injuries caused by GSWs, the criteria still depend on the isolated experience of specialized centers. We suggest multicenter studies in order to unify conducts, resulting in the emergence of a classification with an algorithm that is widely accepted.

The clinical evaluation of the patients was not presented in the present study because, being the initial stage in a line of research, priority was given to addressing the epidemiology and presenting the care protocol, which needs to be validated by future research.

Spinal GSW is a complex injury, and its treatment remains controversial and challenging, Treatment still depends on the choice and experience of the surgeon. Decompression and removal of projectiles causing nerve compression can improve motor function, particularly in incomplete neurological lesions and if performed early. Regardless of the level of the injury, recent onset or progressive neurological deterioration is an indication for urgent decompression. There is a continuing need for well-studied and well-executed protocols that can simplify treatment decisions and further improve the standard of care for this type of injury.

\section{CONCLUSION}

The protocol presented has been systematically applied for more than 15 years and made standardization of conduct in a specialized trauma care center possible.

GSW is an increasingly prevalent injury, yet there are still different ways to manage these patients.

All authors declare no potential conflict of interest related to this article.

CONTRIBUTION OF THE AUTHORS: Each author made significant individual contributions to this manuscript. ALK and ALS: concept of the study, writing of the article, literature review, patient interviews and data analysis; MLB: review of the article; PGS: processing and compilation of the data and literature review; XSIG: review and intellectual concept of the article, final approval of the manuscript for submission.

\section{REFERENCES}

1. Kitchel SH. Current treatment of gunshot wounds to the spine. Clin Orthop Relat Res. 2003;(408):115-9. doi: 10.1097/00003086-200303000-00013

2. Bono CM, Heary RF. Gunshot wounds to the spine. Spine J. Spine J. 2004:4(2):230-40. doi: 10.1016/S1529-9430(03)00178-5

3. Waters RL, Sie $\mathbb{H}$. Spinal cord injuries from gunshot wounds to the spine. Clin Orthop Relat Res. 2003;(408):120-5. doi: 10.1097/00003086-200303000-00014

4. Barros Filho TEP, Oliveira RP, Barros EK, Von Uhlendorff EF, lutaka AS, Cristante AF, et al.
Ferimentos por projétil de arma de fogo na coluna vertebral: estudo epidemiológico. Coluna/Colunma. 2002;1(2):83-7

5. Bathoe HS, Singh P. Missile injuries of the spine. Neurol India. 2003:51(4):507-11

6. Waters RL, Adkins RH, Hu SS, Yakura JS, Sie I. Penetrating injuries of the spinalcord. In: Frymoyer JW, editor. The adult spine: principles and practice. New York: Raven Press; 1991. p. 815-26.

7. Stauffer ES, Wood RW, Kelly EG. Gunshot wounds of the spine: the effects of laminectomy. J Bone Joint Surg Am. 1979;61(3):389-92. 
8. Benato ML, Zaninelli EM, Graells XS. Avaliação da incidência das lesões por arma de fogo da coluna vertebral. Coluna/Columna. 2007;6(3):155-61. doi: 10.1590/S180818512011000400008

9. National Spinal Cord Injury Statistical Center. Spinal cord injury facts and figures at a Glance. Birmingham: University of Alabama; 1999.

10. Mega PT, Lopes ACF, Santos VCC, Petramale CA. Protocolos clínicos e diretrizes terapêuticas no SUS. Rev Gest Saúde. 2015;6(Suppl 4):3275-85.

11. Koch A, Graells XS, Zaninelli EM. Epidemiologia de fraturas de coluna de acordo com o mecanismo de trauma: análise de 502 casos. Coluna/Columna. 2007:6(1):18-23.

12. American College of Surgeons Committee on Trauma. Advanced Trauma Life Support ATLS. 2009.

13. Heary RF, Vaccaro AR, Mesa JJ, Northrup BE, Albert TJ, Balderston RA, et al. Steroids and gunshot wounds to the spine. Neurosurgery. 1997;41(3):576-83; discussion 583-4. doi: 10.1097/00006123-199709000-00013.

14. Bono CM, Heary RF. Gunshot wound to the spine: review article. Spine J. 2004;4(2):230-40 doi: 10.1016/S1529-9430(03)00178-5

15. Jaiswal M, Mittal RS. Concept of Gunshot Wound Spine. Asian Spine J. 2013;7(4):35964. doi: 10.4184/asj.2013.7.4.359

16. Farmer JC, Vaccaro AR, Balderston RA, Albert TJ, Cotler J. The changing nature of admissions to a spinal cord injury center: violence on the rise. J Spinal Disord. 1998;11(5):400-3.

17. Schoenfeld AJ, Laughlin MD, McCriskin BJ, Bader JO, Waterman BR, Belmont PJ, Jr. Spinal injuries in United States military personnel deployed to Iraq and Afghanistan: an epidemiological investigation involving 7877 combat casualties from 2005 to 2009. Spine (Phila Pa 1976). 2013;38(20):1770-8. doi: 10.1097/BRS.0b013e31829ef226.

18. le Roux JC, Dunn RN. Gunshot injuries of the spine-a review of 49 cases managed at the Groote Schuur Acute Spinal Cord Injury Unit. S Afr J Surg. 2005;43(4):165-8.

19. Benzel EC, Hadden TA, Colemam JE. Civilian gunshot wounds to the spinal cord and cauda equina. Neurosurgery. 1987;20(2):281-5. doi: 10.1227/00006123-198702000-00014.

20. Deyo RA, Mirza SK. Trends and variations in the use of spine surgery. Clin Orthop Relat Res. 2006;443:139-46. doi: 10.1097/01.blo.0000198726.62514.75
21. Waters RL, Sie IH. Spinal cord injuries from gunshot wounds to the spine. Clin Orthop Relat Res. 2003;(408):120-5. doi: 10.1097/00003086-200303000-00014.

22. Jakoi A, lorio J, Howell R, Zampini JM. Gunshot Injuries of the Spine. Spine J. 2015;15(9):2077-85. doi: 10.1016/j.spinee.2015.06.007.

23. Oktem IS, Selcuklu A, Kurtsoy A, Kavuncu IA, Pasaoglu A. Migration of bullet in the spinal canal: a case report. Surg Neurol. 1995;44(6):548-50. doi: 10.1016/0090-3019(95)00212-x

24. Fehlings MG, Vaccaro A, Wilson JR, Singh A, Cadotte DW, Harrop JS, et al. Early versus delayed decompression for traumatic cervical spinal cord injury: results of the Surgical Timing in Acute Spinal Cord Injury Study (STASCIS). PLoS One. 2012;7(2):e32037. doi: 10.1371/ journal.pone.0032037.

25. Beazley WC, Rosenthal RE. Lead intoxication 18 months after a 1 gunshot wound. Clin Orthop Relat Res. 1984;(190):199-203.

26. Bolanos AA, Demizio JP Jr, Vigorita VJ, Bryk E. Lead poisoning from an intra-articular 4 shotgun pellet in the knee treated with arthroscopic extraction and chelation therapy. A 5 case report. J Bone Joint Surg Am. 1996;78(3):422-6. doi: 10.2106/00004623-199603000-00014.

27. Levy ML, Gans W, Wijesinghe HS, SooHoo WE, Adkins RH, Stillerman CB. Use of methylprednisolone as an adjunct in the management of patients with penetrating spinal cord injury: outcome analysis. Neurosurgery. 1996;39(6):1141-8. doi: 10.1097/00006123199612000-00014.

28. Botelho RV, Daniel JW, Boulosa JLR, Colli BO, Farias RL, Moraes OJS, et al. Efetividade da metilprednisolona na fase aguda do trauma raquimedular: revisão sistemática dos ensaios clínicos randomizados. Rev Assoc Med Bras. 2009;55(6):729-37. doi: 10.1590/S010442302009000600019

29. Júnior FAA, Belotserkovets HC, Cunha MLV, Veríssimo DCA, Rehder R, Pinto CAS, et al Traumatismo raquimedular por ferimento de projétil de arma de fogo: avaliação epidemiológica. Coluna/Columna. 2011;10(4):290-2. doi: 10.1590/S1808-18512011000400008.

30. Vaccaro AR, Schroeder GD, Kepler CK, Oner FC, Vialle LR, Kandziora F, et al. The surgical algorithm for the AOSpine thoracolumbar spine injury classification system. Eur Spine J. 2016;25(4):1087-94. doi: 10.1007/s00586-015-3982-2. 